\title{
Extracellular Signal-Regulated Kinases Regulate Dendritic Growth in Rat Sympathetic Neurons
}

\author{
In-Jung Kim, ${ }^{1 \star}$ Karen M. Drahushuk, ${ }^{1 \star}$ Woo-Yang Kim, ${ }^{1}$ Eugene A. Gonsiorek, ${ }^{1}$ Pamela Lein, ${ }^{2}$ Douglas A. Andres, ${ }^{3}$ and \\ Dennis Higgins ${ }^{1}$ \\ ${ }^{1}$ Department of Pharmacology and Toxicology, State University of New York, Buffalo, New York 14214, ${ }^{2}$ Center for Research on Occupational and \\ Environmental Toxicology, Oregon Health \& Sciences University, Portland, Oregon 97239, and ${ }^{3}$ Department of Molecular and Cellular Biochemistry, \\ University of Kentucky, College of Medicine, Lexington, Kentucky 40536-0298
}

NGF activates several signaling cascades in sympathetic neurons. We examined how activation of one of these cascades, the ERK/MAP (extracellular signal-regulated kinase/mitogen-activated protein) kinase pathway, affects dendritic growth in these cells. Dendritic growth was induced by exposure to NGF and BMP-7 (bone morphogenetic protein-7). Exposure to NGF increased phosphorylation of ERK1/2. Unexpectedly, two MEK (MAP kinase kinase) inhibitors (PD 98059 and U 0126) enhanced dendritic growth, and a ligand, basic FGF, that activates the ERK pathway inhibited the growth of these processes. The enhancement of dendritic growth by PD 98059 was associated with an increase in the number of axo-dendritic synapses, and it appeared to represent a specific morphogenic effect because neither axonal growth nor cell survival was affected. In addition, increased dendritic growth was not observed after exposure to inhibitors of other signaling pathways, including the phosphatidylinositol-3-kinase inhibitor LY 294002. Dendritic growth was also increased in cells transfected with dominant-negative mutants of MEK1 and ERK2 but not with dominant-negative mutants of MEK5 and ERK5, suggesting that ERK1/2 is the primary mediator of this effect. Exposure to BMP-7 induces nuclear translocation of Smad1 (Sma- and Mad-related protein 1), and PD 98059 treatment potentiated nuclear accumulation of Smad-1 induced by BMP-7 in sympathetic neurons, suggesting a direct enhancement of BMP signaling in cells treated with an MEK inhibitor. These observations indicate that one of the signaling cascades activated by NGF can act in an antagonistic manner in sympathetic neurons and reduce the dendritic growth induced by other NGF-sensitive pathways.

Key words: ERK; dendrite; BMP; NGF; MAP kinase; MEK

\section{Introduction}

Dendrites are the primary site of synapse formation in the vertebrate nervous system. Therefore, it is important to understand how the growth of these processes is regulated. Many growth factors have been found to stimulate dendritic growth (Higgins et al., 1997), but two families appear to have especially prominent and widespread effects. Members of the BMP (bone morphogenetic protein) family enhance dendritic growth in sympathetic, spinal motor, cortical, striatal, and hippocampal neurons (Lein et al., 1995; Withers et al., 2000; Esquenazi et al., 2002; Gratacos et al., 2002), whereas various neurotrophins increase the growth of these processes in cortex (McAllister et al., 1995; Baker et al., 1998), retina (Lom et al., 2002), and cerebellum (Schwartz et al., 1997). Moreover, there is evidence for interactions between these

\footnotetext{
Received July 10, 2003; revised Feb. 13, 2004; accepted Feb. 13, 2004.

This study was supported by National Science Foundation Grant IBN0121210 (D.H.) and National Institute of Neurological Disorders and Stroke Grant NS46649 (P.L.). We thank Drs. Natalie G. Ahn (University of Colorado, Boulder, (0) and Jiing-Dwan Lee (Scripps Research Institute, La Jolla, CA) for kindly providing plasmids carrying mutant MEK and ERK genes.

*I.-J.K and K.M.D contributed equally to this work.

Correspondence should be addressed to Dennis Higgins, State University of New York at Buffalo, 102 Farber Hall, 3435 Main Street, Buffalo, NY 14214. E-mail: higginsd@acsu.buffalo.edu.

DOI:10.1523/JNEUROSCI.3286-03.2004

Copyright $\odot 2004$ Society for Neuroscience $\quad$ 0270-6474/04/243304-09\$15.00/0
}

two classes of stimulatory molecules, with sympathetic neurons requiring simultaneous exposure to both a member of the BMP family and to nerve growth factor (NGF) for optimal dendritic growth (Lein et al., 1995). A variety of cytokines and hormones have also been found to inhibit dendritic growth (Guo et al., 1999; Chandrasekaran et al., 2000; Drahushuk et al., 2002; Kim et al., 2002). However, the signaling cascades triggered by these stimulatory and inhibitory agents and their interactions remain poorly characterized.

The binding of neurotrophins to trk receptors activates several signaling pathways. These include the ERK (extracellular signal-regulated kinase) cascade, PI-3 kinase (phosphatidylinositol-3-kinase)/Akt kinase, and phospholipase C (PLC)- $\gamma 1$ (Huang and Reichardt, 2001; Chao, 2003). Of particular interest is the ERK pathway, which has many effects on neural tissues. For example, activation of ERKs increases axonal growth in sympathetic neurons (Atwal et al., 2000), dorsal root ganglia (Sjogreen et al., 2000; Wiklund et al., 2002), and PC12 cells (Traverse et al., 1992; Pang et al., 1995) in vitro, and it also enhances axonal regeneration after axotomy in vivo (Miura et al., 2000). In addition, ERK stimulation plays an important role in activity-dependent regulation of neuronal functions, such as synaptic plasticity, learning, and memory (Grewal et al., 1999; Adams and Sweatt, 2002). In this study, we examined the role of the ERK pathway in 
the regulation of dendritic growth in sympathetic neurons exposed to BMP-7 and NGF. Costimulation with these two agents leads to a rate of dendritic growth in vitro that is equivalent to that observed in vivo (Lein et al., 1995), and there is evidence for sympathetic neurons being exposed to both of these growth factors in vivo, with NGF being derived from target tissues (Purves et al., 1988) and BMPs being produced by glia (Lein et al., 2002).

Our data indicate that inhibition of ERK1/2 activation by either pharmacological agents or overexpression of dominantnegative mutants potentiates dendritic growth in the presence of BMPs and NGF and that this represents a specific morphogenetic effect because neither axonal growth nor cell survival is affected. These observations indicate that one of the signaling cascades activated by NGF acts in an antagonistic manner in sympathetic neurons and reduces the dendritic growth induced by other NGF-sensitive signaling pathways.

\section{Materials and Methods}

Materials. Recombinant human BMP-2, BMP-6, and BMP-7 were generous gifts from Curis (Cambridge, MA). PD 98059 was purchased from Biomol (Plymouth Meeting, PA), and U 0126 was from Promega (Madison, WI). LY 294002 was obtained from Sigma (St. Louis, MO), and SB 202190 was from Calbiochem (San Diego, CA).

Cell culture. Cultures of neurons from the superior cervical ganglia of embryonic (day 21) Holtzman rats (Harlan Sprague Dawley, Rockford, IL) were prepared according to previously described methods (Higgins et al., 1991). Briefly, cells were dissociated after enzymatic treatment with trypsin $(2.5 \mathrm{mg} / \mathrm{ml})$ and collagenase $(1 \mathrm{mg} / \mathrm{ml})$. Subsequently, they were pelleted, resuspended in serum-free medium, and plated at low density $\left(\sim 10\right.$ cells $\left./ \mathrm{mm}^{2}\right)$ onto poly-D-lysine- $(100 \mu \mathrm{g} / \mathrm{ml})$ coated coverslips. The serum-free culture medium (Higgins et al., 1991) contained $\beta$-NGF (100 $\mathrm{ng} / \mathrm{ml})$. To kill dividing non-neuronal cells, the anti-mitotic agent cytosine- $\beta$-D-arabinofuranoside $(1 \mu \mathrm{M})$ was added to the medium for 48 $\mathrm{hr}$ beginning on day 2. Experimental treatments were begun on the sixth or seventh day in vitro.

Morphological analyses. Cellular morphology was analyzed by immunocytochemical methods (Lein et al., 1995). Culture were fixed with $4 \%$ paraformaldehyde and permeabilized with $0.1 \%$ Triton X-100 in PBS (3 $\mathrm{min})$. Cells were then incubated with monoclonal antibodies $(\mathrm{mAb})$ that recognize either axons or dendrites, followed by detection with rhodamine-conjugated secondary antisera (Roche Products, Indianapolis, IN). An mAb to MAP2 (microtubule-associated protein-2) (SMI-52; Sternberger Monoclonals, Baltimore, MD) was used to visualize dendrites. Axons were identified with an $\mathrm{mAb}$ to phosphorylated forms of the heavy (NF-H) and medium (NF-M) neurofilament subunits (SMI31; Sternberger Immunocytochemicals). SPOT software (Diagnostic Instruments, Sterling Heights, MI) was used to measure the total neuritic length. Synaptic specializations that formed along dendrites were visualized by double labeling the cultures with rabbit anti-MAP2 IgG (a gift from Dr. Craig Garner, University of Alabama at Birmingham, Birmingham, AL) and mAb to SV2 (synaptic vesicle protein-2) (Developmental Studies Hybridoma Bank, University of Iowa, Iowa City, IA) (Feany et al., 1992) and then with rhodamine-conjugated antibody to rabbit IgG and fluorescein-conjugated antibody to mouse IgG (Roche Products).

Axonal growth was also assessed by plating cells at low density $(\sim 3000$ cells per coverslip) onto gridded coverslips with embossed coordinates (CELLocate; Eppendorf Scientific, Hamburg, Germany). Under these conditions, one can serially monitor axonal growth for extended periods by relocating previously examined neurons (Guo et al., 1999). After eliminating non-neuronal cells, neurons were grown in medium with or without PD 98059 for $5 \mathrm{~d}$, and total axonal length was periodically measured with NIH Image $\mathrm{J}$ (version 1.25s).

The rabbit IgG fraction used to examine the cellular distribution of Smad-1 (Sma- and Mad-related protein 1) was obtained from Upstate Biotechnology (Lake Placid, NY). Briefly, cultures were fixed with $4 \%$ paraformaldehyde $\left(15 \mathrm{~min}, 20^{\circ} \mathrm{C}\right)$ and permeabilized with methanol (10 min, $-20^{\circ} \mathrm{C}$ ). Cells were examined with a Bio-Rad (Hercules, CA) confocal microscope, using $1 \mu \mathrm{m}$ optical sections.

Experiments were typically performed three times, and data are presented as the mean \pm SEM. Statistical significance was assessed by Student's $t$ test or a one-way ANOVA, followed by Tukey's post hoc test.

Western blotting. Cells were solubilized in $50 \mathrm{~mm}$ Tris- $\mathrm{HCl}, \mathrm{pH}$ 7.4, 1 mм EDTA, $0.1 \%$ SDS, and 2.0\% $\beta$-mercaptoethanol. After centrifugation at $15,000 \times g$ for $10 \mathrm{~min}$, the protein concentration was determined using a Bio-Rad protein assay. Proteins ( $10 \mu \mathrm{g} / \mathrm{lane})$ were separated by SDS-PAGE (12\%) and transferred to polyvinylidene difluoride membranes. Blots were probed with polyclonal antibodies to ERK1/2 or phosphorylated-ERK1/2 (Cell Signaling Technology, Beverly, MA) or an mAb to MAP2 (SMI-52) and incubated with HRP-conjugated secondary antibodies (Boehringer Mannheim, Indianapolis, IN). Detection was performed using an enhanced chemiluminescent reagent (Amersham Biosciences, Piscataway, NJ). To quantify data, films were scanned using an HP ScanJet ADF scanner and HP Precision ScanPro software (HewlettPackard, Palo Alto, CA), and band density was determined as arbitrary absorption units.

Transfection. Cells were cotransfected with a plasmid encoding the enhanced green fluorescent protein (pEGFP-N2; Clontech, Palo Alto, $\mathrm{CA}$ ) and plasmids containing either MEK [MAP (mitogen-activated protein) kinase kinase] or ERK constructs. The former were a generous gift from Dr. Natalie Ahn (University of Colorado, Boulder, CO) and consisted of the expression vector pMCL containing HA-MAPKK [hemagglutinin-mitogen-activated protein kinase kinase (wild type)], HA-K97M MAPKK (dominant-negative carrying $M$ substitution at K97), or HA-S218E/S222D MAPKK (constitutively active) (Mansour et al., 1994). Dominant-negative ERK2, ERK5, and MEK5 constructs (Kato et al., 1997) were kindly provided by Dr. Jiian-Dwan Lee (Scripps Research Institute, La Jolla, CA). Transfection was performed using LipofectAmine 2000 (Invitrogen, Carlsbad, CA) according to the protocol of the manufacturer. Briefly, cells in 12-well dishes were treated on day 5 with $500 \mu \mathrm{l} /$ well of DMEM containing $1.5 \mu \mathrm{g}$ of DNA and $6 \mu \mathrm{g}$ of LipofectAmine. After incubation for $6 \mathrm{hr}$, cells were washed and allowed to recover for $48 \mathrm{hr}$ before experimental treatments were begun. Transfection efficiency was typically $\sim 20 \%$ (Kim et al., 2002).

\section{Results}

\section{Inhibition of MEK enhances dendritic growth and} synapse formation

Embryonic sympathetic neurons extend only axons (Bruckenstein and Higgins, 1988a) when grown in serum-free medium in the absence of non-neuronal cells (Fig. 1). Exposure to a modest concentration $(10 \mathrm{ng} / \mathrm{ml})$ of BMP-7 causes these neurons to form two to three dendrites over $5 \mathrm{~d}$ (Fig. 1). Neurons treated with maximally effective doses ( $\geq 50 \mathrm{ng} / \mathrm{ml}$ ) of BMP-7 extend a greater number of primary dendrites (Fig. 2) and eventually generate a dendritic arbor that is equivalent in size to that observed in situ (Lein et al., 1995).

We wanted to examine the possibility that the MAPK pathway regulates dendritic growth. Sympathetic neurons were grown in the presence of a maximally effective concentration $(100 \mathrm{ng} / \mathrm{ml})$ of NGF. Therefore, it was expected that the MEK/MAPK pathway would be active under our culture conditions (Creedon et al., 1996). To assess morphological changes in dendrites, cells were exposed to an inhibitor of MEK1 (PD 98059) with or without BMP-7 (10 ng/ml) for $5 \mathrm{~d}$. PD 98059 alone did not induce morphological changes in sympathetic neurons (Fig. 1). However, it potentiated the inductive effects of BMP-7 on dendritic growth. The potentiating effects of PD 98059 were detected at concentrations as low as $0.1 \mu \mathrm{M}$, and the $\mathrm{ED}_{50}$ was $\sim 0.3 \mu \mathrm{M}$ (Fig. 2). In cultures treated with moderate doses of BMP-7 (10 ng/ml), PD 98059 produced a twofold increase in the number of dendrites, and total dendritic length increased threefold (Fig. 2). The potentiating effects of PD 98059 were also observed in the presence of 

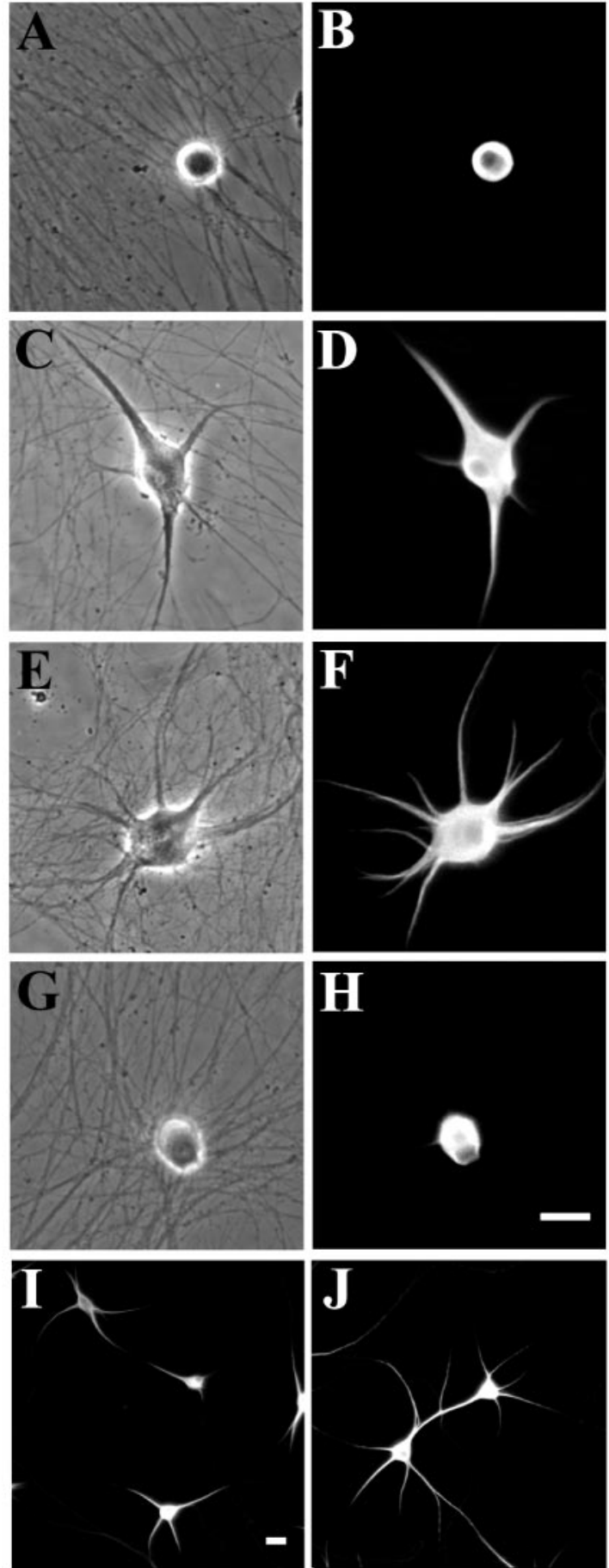

Figure 1. Effects of BMP-7 and PD 98059 on the morphology of sympathetic neurons. Phasecontrast $(A, C, E, G)$ and fluorescence $(B, D, F, H-J)$ micrographs of neurons immunostained with an $\mathrm{mAb}$ to MAP2. Neurons in control cultures had only axons $(A, B)$. Neurons exposed to BMP-7 $(10 \mathrm{ng} / \mathrm{ml})$ for 5 d extended dendrites $(C, D)$, and this response was enhanced by treatment with PD $98059(10 \mu \mathrm{m} ; E, F)$. PD 98059 alone had no effect on dendritic growth $(G, H)$. I and $J$ are low-power micrographs of cells exposed to BMP alone $(/)$ or in the presence of PD $98059(J)$. Scale bars, $25 \mu \mathrm{m}$.

maximally effective concentrations of BMP-7 $(>50 \mathrm{ng} / \mathrm{ml})$ : there was an $\sim 50 \%$ increase in the number of dendrites and a $\sim 35 \%$ increase in total dendritic length. Nonlinear regression analysis (Marquardt-Levenberg algorithm) revealed that PD 98059 increased the maximum response, i.e., it increased the number of dendrites that sympathetic neurons develop in cul- ture but did not affect the $\mathrm{ED}_{50}$. These data suggest that the effect of PD 98059 on BMP-7-induced dendritic growth is an enhancement of BMP-7 efficacy. PD 98059 also enhanced BMP-2- and BMP-6-induced dendritic growth (data not shown), suggesting that PD 98059 affects a common pathway in BMP signaling.

To further characterize the effects of MEK inhibition on sympathetic neurons, we examined the effects of PD 98059 on MAP2 expression and synapse formation. MAP2 is a protein that is found primarily in dendrites, and its expression increases after exposure to BMP-7 (Guo et al., 1998). In agreement with previous reports, Western blotting revealed that the expression of MAP2 increased $2.8 \pm 0.2$-fold after $48 \mathrm{hr}$ of BMP-7 exposure. In the presence of PD 98059, the increase in MAP2 expression was greater (3.5 \pm 0.1 -fold increase), suggesting a modest synergistic action on MAP2 expression. Treatment with PD 98059 also increased the formation of axo-dendritic synapses by $46 \%$ (Fig. 3). Thus, MEK inhibition not only enhances the growth of dendrites but also increases the number of contacts made with these processes.

To confirm that MEK was indeed active in our system and that PD 98059 blocked its activity, we examined the activation of ERK1/2, which are kinases downstream from MEK. Western blotting was performed, using an antibody that recognizes a phosphorylated form of ERK1/2 (Thr 202/Tyr 204). Pretreatment of cells with PD $98059(10 \mu \mathrm{M})$ for $30 \mathrm{~min}$ completely inhibited the phosphorylation of ERK1/2 produced by NGF (100 $\mathrm{ng} / \mathrm{ml}$ ) (data not shown). The specificity of action of PD 98059 was further assessed by comparing its effects with those of a structurally unrelated MEK inhibitor, U 0126 (Fig. 4). A 2.5-fold increase in the number of dendrites per cell was observed in cultures treated with U 0126 in the presence of BMP-7, strongly suggesting that the potentiation of dendritic growth by PD 98059 is attributable to its ability to inhibit MEK.

We next determined whether a dominant-negative mutant of MEK1 that is catalytically inactive (K97M) also enhances BMP7 -induced dendritic growth. For these transfection experiments, we needed to use higher-density cultures in which dendritic growth was less robust than in low-density cultures used in other experiments (Fig. 5). However, inhibition of MEK also enhanced dendritic growth in these cultures (data not shown). Wild-type or mutant MEK1 was cotransfected with EGFP to identify the transfected cells. Forty-eight hours later, cells were treated with BMP-7 $(10 \mathrm{ng} / \mathrm{ml})$ for $5 \mathrm{~d}$. In cultures transfected with control vector or wild-type MEK1, BMP-7 caused cells to extend approximately one dendrite, indicating that transfected cells responded to BMP-7 (Fig. 5). Consistent with previous results, overexpression of the dominant-negative mutant of MEK1 potentiated BMP-7induced dendritic growth by $\sim 1.8$-fold. Moreover, constitutively active MEK1 decreased dendritic growth, strongly suggesting that the ERK/MAPK pathway regulates dendritic growth in sympathetic neurons.

NGF causes activation of both ERK1/2 and ERK5 in sympathetic neurons, and there is evidence indicating the various ERKs subserve different cellular functions in these cells (Watson et al., 2001). To determine whether a particular isoform was involved in the regulation of dendritic growth, sympathetic neurons were transfected with dominant-negative constructs of ERK2 and ERK5. Only the former enhanced dendritic growth (Fig. 6). Dominant-negative mutants of ERK5 and MEK5, the kinase upstream of ERK5, were inactive. 
A

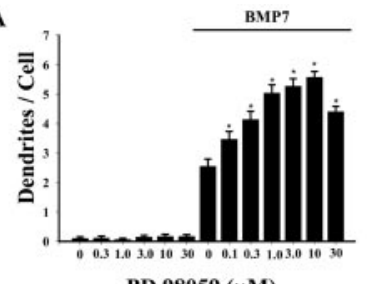

PD $98059(\mu \mathrm{M})$

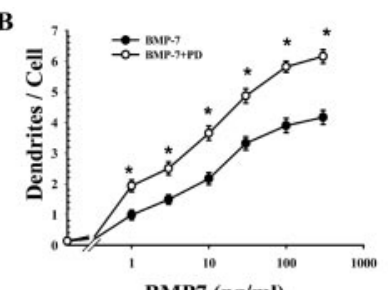

BMP7 (ng/ml)

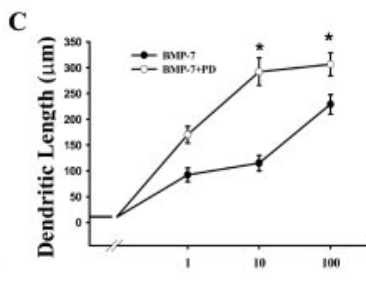

BMP7 (ng/ml)

Figure 2. Inhibition of MEK1 enhances BMP-7-induced dendritic growth. Sympathetic neurons were exposed to various concentrations of the MEK inhibitor PD 98059 (PD) ( $A$ ) with or without BMP-7 (10 ng/ml) for 5 d. Alternatively, cells were exposed to varying concentrations of BMP-7 $(B, C)$ in the presence of PD $98059(10 \mu \mathrm{M})$. The number of dendrites per cell $(B)$ and total dendritic length ( $C$ ) was assessed by immunostaining with mAb to MAP2 ( $n \geq 60$ cells). ${ }^{*} p<0.05$ versus control.

$\mathbf{A}$
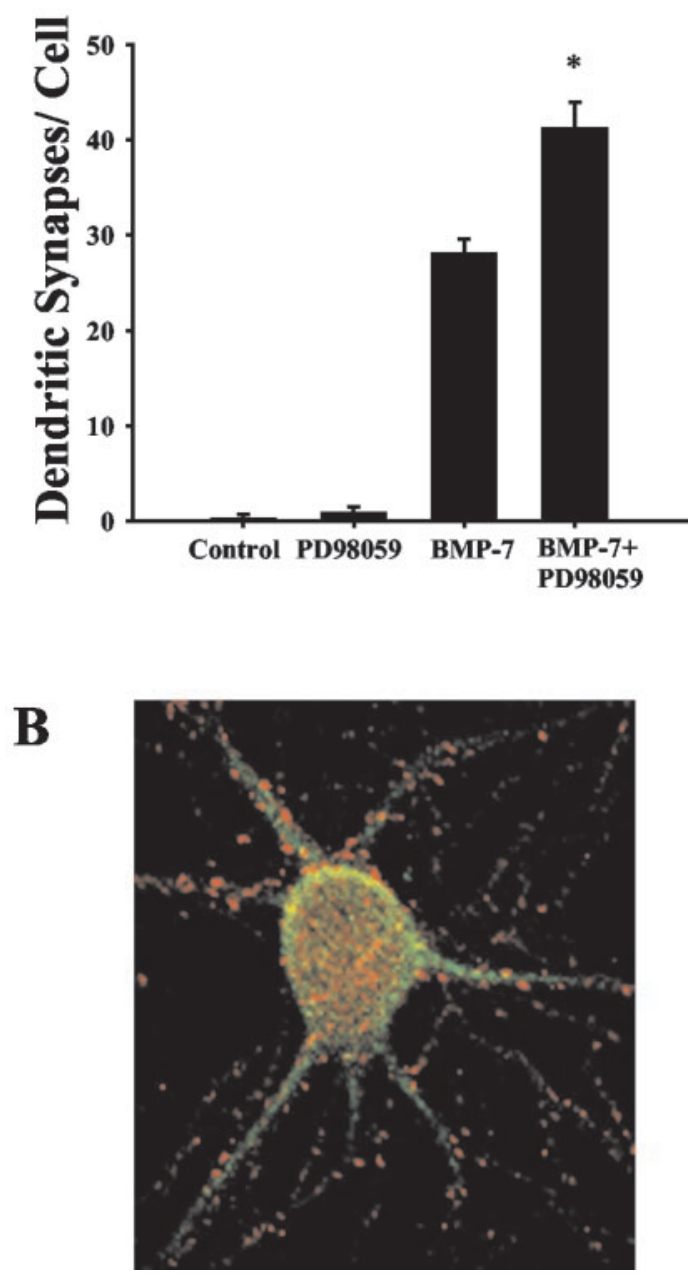

Figure 3. Effects of an MEK inhibitor on synapse formation in cultures of sympathetic neurons. A, Neurons were treated with BMP-7 $(10 \mathrm{ng} / \mathrm{ml})$ with or without PD $98059(10 \mu \mathrm{m})$ for $5 \mathrm{~d}$. Dendritic morphology and presynaptic specializations were analyzed by double immunostaining with antibodies to MAP2 (green) and SV2 (red) ( $n \geq 30$ cells per condition). SV2-positive puncta that are associated with dendrites have been shown previously to represent sites of synaptic contact (Fletcher et al., 1994). ${ }^{*} p<0.05$ versus control. $B$, Fluorescence micrograph of a neuron treated with BMP-7 (10 ng/ml) and PD 98059 (10 $\mu \mathrm{m})$ for $5 \mathrm{~d}$.

MAP kinase does not affect cell number or axonal growth To determine whether PD 98059 selectively affects dendrites, we examined its effects on cell survival. There was no significant change in neuronal number in the presence of a maximally effective concentration $(10 \mu \mathrm{M})$ of PD 98059 (Fig. 7). This finding is consistent with previous reports that inhibition of MEK activity by PD 98059 does not suppress the survival of sympathetic neurons (Creedon et al., 1996; Virdee and Tolkovsky, 1996).

Inhibition of MEK activation inhibits neuritic growth in PC12 cells (Cowley et al., 1994; Pang et al., 1995) and axonal regeneration after axotomy in sensory neurons of the dorsal root ganglia (Sjogreen et al., 2000; Wiklund et al., 2002). Therefore, we used two methods to determine whether PD 98059 affects axonal growth in our system (Fig. 8). First, initial axonal outgrowth was assessed at $12 \mathrm{hr}$ after plating. Immunostaining with an antibody that recognizes the phosphorylated forms of NF-H and NF-M showed that PD 98059 does not interfere with initial axonal growth. To examine possible long-time effects of PD 98059 on axonal growth, neurons were plated onto gridded coverslips at low density, which allowed us to observe morphological changes of individual axons in the same region over time (Fig. 8). Treatment with PD 98059 began on day 5 in vitro, at which time a minimal level of axonal growth had been established. Total axonal length was reassessed 1, 3, and $5 \mathrm{~d}$ later, and serial imaging showed that the inhibition of MEK activity does not affect axonal growth. These data suggest that MAP kinase selectively affects dendritic growth in sympathetic neurons grown under serum-free conditions.

\section{Comparison of effects of MEK inhibitors and other kinase inhibitors}

The p38 kinase, a member of the MAPK subfamily, has also been implicated in neuronal differentiation, including NGF-induced neuritic growth of PC12 cells (Morooka and Nishida, 1998; Hansen et al., 2000). In addition, PI-3 kinase is activated by neurotrophic factors that regulate the axonal growth and survival of sympathetic neurons (Kuruvilla et al., 2000). To determine whether these kinases regulate dendritic growth, sympathetic neurons were exposed to SB 203580, a p38 kinase inhibitor, or the PI-3 kinase inhibitor LY 294002 , in the presence of BMP-7 (10 ng/ml) for $5 \mathrm{~d}$ (Table 1). Neither inhibitor potentiated BMP-7-induced dendritic growth. The inhibition of dendritic growth by LY 294002 may be attributable to its deleterious effects on sympathetic neuronal health survival (Crowder and Freeman, 1998; Mazzoni et al., 1999), and somatic atrophy was observed in our cultures.

\section{FGF inhibits BMP-7-induced dendritic growth}

We next determined whether other growth factors that activate the ERK pathway also inhibit BMP-7-induced dendritic growth. Neurons were cultured in the media containing $10 \mathrm{ng} / \mathrm{ml} \mathrm{NGF}$. This concentration of NGF allows high rates of survival (90$100 \%$ ) of sympathetic neurons (Belliveau et al., 1997). However, it is suboptimal for promoting dendritic growth and thus provides favorable conditions for examining effects of FGF-induced ERK activation on dendritic growth. In cultures treated with moderate doses of BMP-7 ( $5 \mathrm{ng} / \mathrm{ml})$, there was a $45 \%$ decrease in the number of dendrites per cell in the presence of FGF (Fig. 9), suggesting that FGF-induced ERK activation inhibits dendritic growth in sympathetic neurons.

\section{MAPK blocks the nuclear accumulation of Smad-1}

MAPK has been shown to inhibit the nuclear accumulation of Smad-1 by phosphorylating a site in the linker region between the 


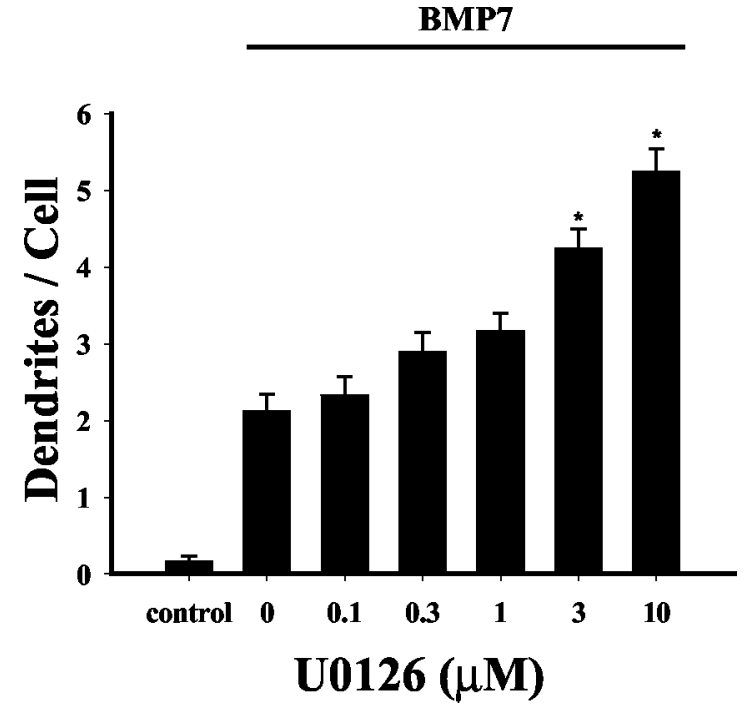

Figure 4. Effects of U 0126 on dendritic growth. Sympathetic neurons were exposed to various concentrations of the MEK inhibitor U 0126 with or without BMP-7 $(10 \mathrm{ng} / \mathrm{ml})$ for $5 \mathrm{~d}$. Cellular morphology ( $n \geq 60$ cells) was assessed by immunostaining with mAb to MAP2. ${ }^{*} p<$ 0.05 versus BMP-7 alone.
A
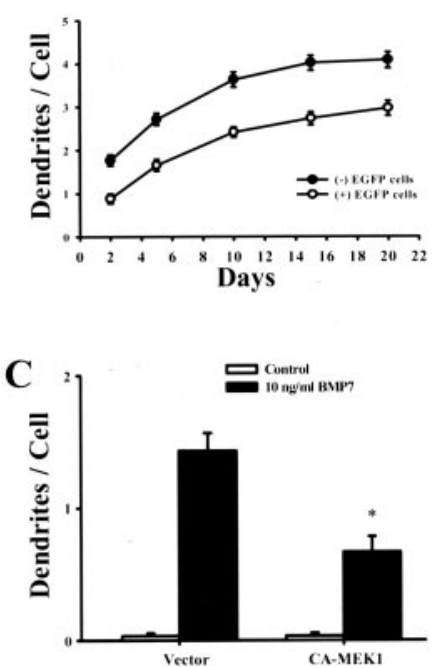

B

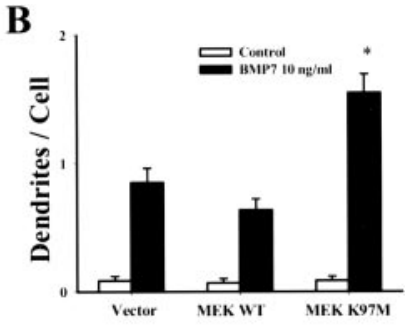

D

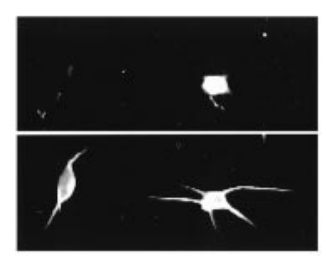

Figure 5. Dominant-negative MEK1 potentiates BMP-7-induced dendritic growth. For transfections, sympathetic neurons were plated at threefold higher density $\left(\sim 30\right.$ cells $\left./ \mathrm{mm}^{2}\right)$ than in previous experiments. Under these conditions, BMP-7 $(10 \mathrm{ng} / \mathrm{ml})$ still induced dendritic growth, but the magnitude of the response was reduced $(A)$. Neurons were cotransfected with plasmids containing EGFP and wild-type MEK1 (MEK1 WT) or dominant-negative mutant (MEK1 K97M) ( $B$ ) or with a constitutively active mutant ( $($ ). Two days later, cells were treated with BMP-7 $(10 \mathrm{ng} / \mathrm{ml})$. On day 5 , cellular morphology was assessed by immunostaining with an mAb to MAP2 ( $D$, bottom; $n \geq 60$ per group). Fluorescence micrograph of a nontransfected neuron and a neuron cotransfected with EGFP and dominant-negative MEK (MEK1 K97M) (D). Transfected cells were identified by expression of EGFP $\left(D\right.$, top). ${ }^{*} p<0.05$ versus BMP-7.

DNA-binding domain and the transcriptional activation domain (Kretzschmar et al., 1997). To explore the mechanism involved in MAPK-mediated regulation of dendritic growth, we examined the possibility that the inhibition of MAPK activity enhances nuclear accumulation of Smad-1. Treatment with a maximally effective concentration of BMP-7 (100 ng/ml) caused marked induction and nuclear translocation of Smad-1 within $2 \mathrm{hr}(\sim 90 \%$ nuclei labeled) (Fig. 10). In contrast, treatment of BMP-7 at a

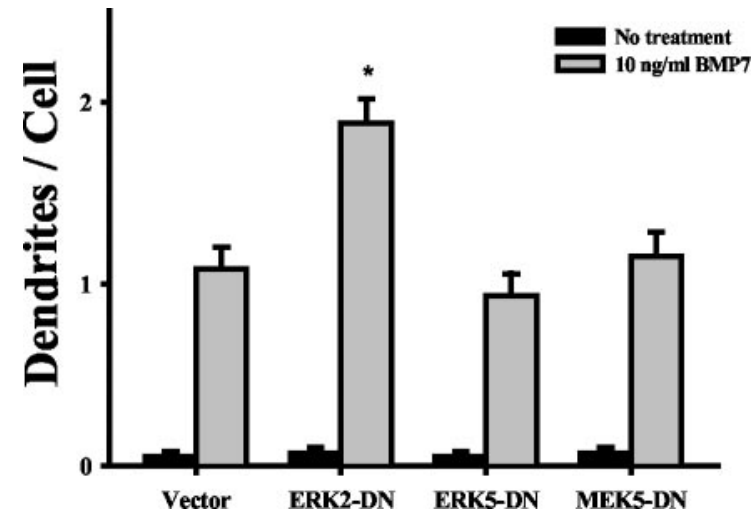

Figure 6. Dominant-negative ERK2 enhances dendritic growth. Sympathetic neurons were cotransfected with plasmids containing EGFP and one of the following constructs: dominantnegative ERK2 (AEF; Thr 183 and Tyr 185 replaced with alanine and phenylalanine) (Kato et al., 1997), dominant-negative ERK5 (AEF), or dominant-negative MEK5 (A). Two days later, cells were treated with BMP-7 $(10 \mathrm{ng} / \mathrm{ml})$. On day 5 , cellular morphology was assessed by immunostaining with an mAb to MAP2. Transfected cells were identified by expression of EGFP. ${ }^{*} p<$ 0.05 versus BMP- 7 .

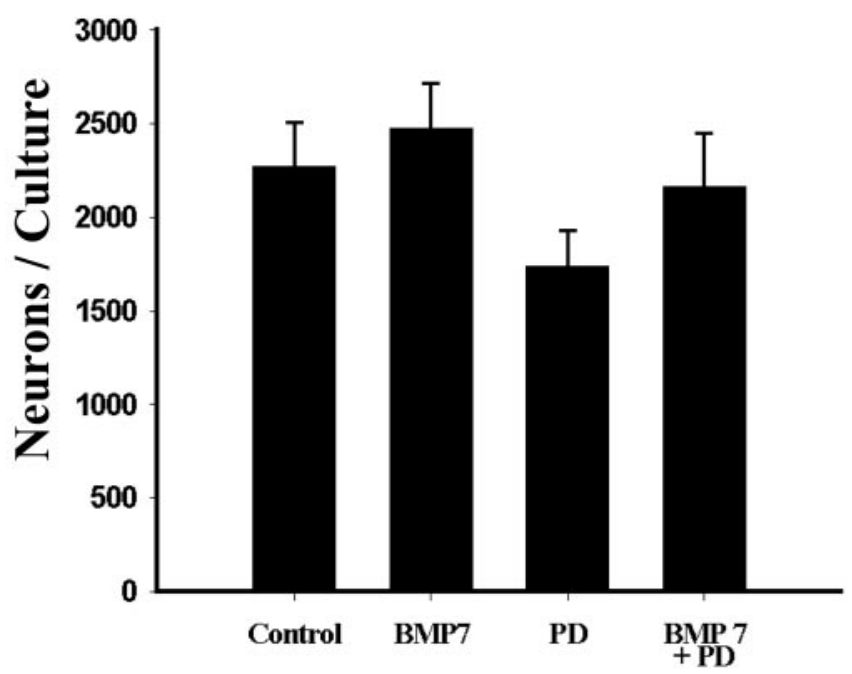

Figure 7. Inhibition of MEK1 does not alter cell survival. Sympathetic neurons were treated with BMP-7 $(10 \mathrm{ng} / \mathrm{ml})$ with or without PD 98059 (PD) $(10 \mu \mathrm{m})$ for $5 \mathrm{~d}$. Subsequently, cell survival was determined by counting the number of MAP2-positive cells.

concentration approximating the $\mathrm{EC}_{50}(10 \mathrm{ng} / \mathrm{ml})$ did not cause a detectable effect at this time; most cells still showed modest Smad-1 staining in the cytoplasm ( $\sim 15 \%$ nuclei labeled). These data indicate that lower concentrations of agonist cause a decrease in the kinetics of signaling events mediated by BMP-7. However, PD 98059 treatment potentiated the induction and nuclear accumulation of Smad-1 ( $\sim 42 \%$ nuclei labeled) compared with treatment with the lower concentration of BMP-7 alone.

\section{Discussion}

The ERK signaling pathway regulates crucial aspects of neuronal development, including cellular survival and differentiation (Traverse et al., 1992; Pang et al., 1995; Bergmann et al., 1998; Kurada and White, 1998; Anderson and Tolkovsky, 1999; Atwal et al., 2000; Wiklund et al., 2002). Activation of the ERK signaling pathway has also been found to alter axonal growth in sympathetic, sensory, and spinal motor neurons (Atwal et al., 2000; 
A

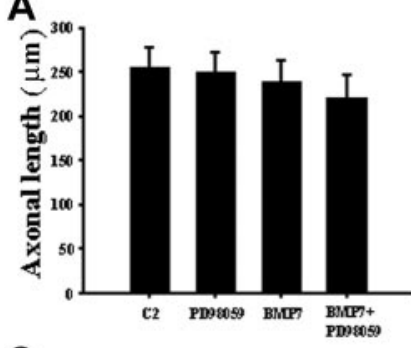

C

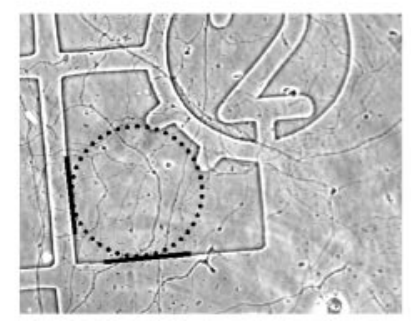

B

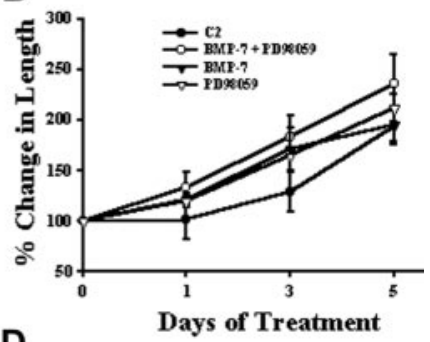

D

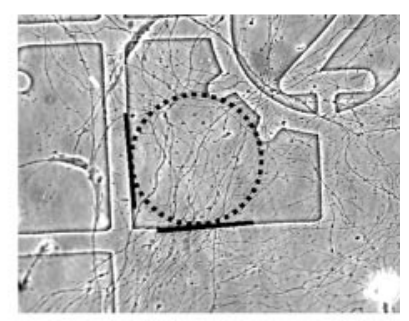

Figure 8. Inhibition of MEK1 activity does not affect axonal growth. $A$, Dissociated neurons were plated onto coverslips coated with laminin $(2 \mu \mathrm{g} / \mathrm{ml})$ in control medium (C2) or in the presence of PD 98059 (10 $\mu \mathrm{m})$ and/or BMP-7 (10 ng/ml) for $12 \mathrm{hr}$. Axons were identified by immunostaining with an mAb that recognizes phosphorylated forms of NF-H and NF-M ( $n \geq 40$ cells). $B-D$, Neurons were plated at low density onto gridded coverslips. After elimination of non-neuronal cells, neurons were grown in medium with or without PD $98059(10 \mu \mathrm{m})$ and/or BMP-7 $(10 \mathrm{ng} / \mathrm{ml})$ for $5 \mathrm{~d}$. Representative areas of the cultures were photographed just before treatments and after 1, 3, and $5 \mathrm{~d}$ of treatment. The total linear length of all axonal processes with the designated area was determined using NIH Image J software. C, Phase-contrast micrograph of a representative area, taken before experimental treatment was begun. When the same area was relocated after $5 \mathrm{~d}$ of treatment with PD 98059, the axonal network had become much denser and new processes had appeared $(D)$. Circle represents the defined area inside which axons were serially traced; dark lines indicate alignment reference points for repeated placement of saved circle template. $B$, Total axonal length (15 areas).

Table 1. Comparison of effects of MEK inhibitors and other kinase inhibitors on BMP-7-induced dendritic growth

\begin{tabular}{ll}
\hline Treatment & Dendrites per cell \\
\hline BMP-7 & $3.21 \pm 0.21$ \\
BMP-7 + PD 98059 & $5.37 \pm 0.22^{*}$ \\
BMP-7 + U 0126 & $5.98 \pm 0.24^{*}$ \\
BMP-7 + SB 202190 & $3.38 \pm 0.18$ \\
BMP-7 + LY 294002 & $1.97 \pm 0.14^{*}$ \\
\hline
\end{tabular}

Sympathetic neurons were exposed to BMP-7 $(10 \mathrm{ng} / \mathrm{ml})$ alone or with one of following kinase inhibitors for $5 \mathrm{~d}$ : PD $98059(10 \mu \mathrm{M}), \mathrm{U} 0126(10 \mu \mathrm{M}), \mathrm{SB} 202190(10 \mu \mathrm{M})$, or LY 294002 (10 $\mu \mathrm{M})$. Dendrites were detected by immunostaining with a mAb to MAP2. ${ }^{*} p<0.05$ versus BMP-7.

Miura et al., 2000; Sjogreen et al., 2000; Wiklund et al., 2002) and neurite outgrowth in PC 12 cells (Traverse et al., 1992; Pang et al., 1995). In most instances, the effects of ERK activation on axonal growth have been stimulatory. In contrast, our data indicate that inhibition of ERK signaling enhances BMP-7-induced dendritic growth and synapse formation, indicating that activation of this pathway may adversely affect neural development under some circumstances.

Our observations contrast with a recent reporting suggesting that ERKs mediate activity-dependent increases in dendritic growth. In particular, Vaillant et al. (2002) found that depolarization of sympathetic neurons via exposure to $\mathrm{KCl}$ stimulates the ERK pathway and that this increases dendritic stability. Subtle differences in the culture systems, such as the use of serum (Bruckenstein and Higgins, 1988b) by Vaillant et al., may underlie these discrepant results. However, it should be noted that basal dendritic growth was limited in their control cultures (average

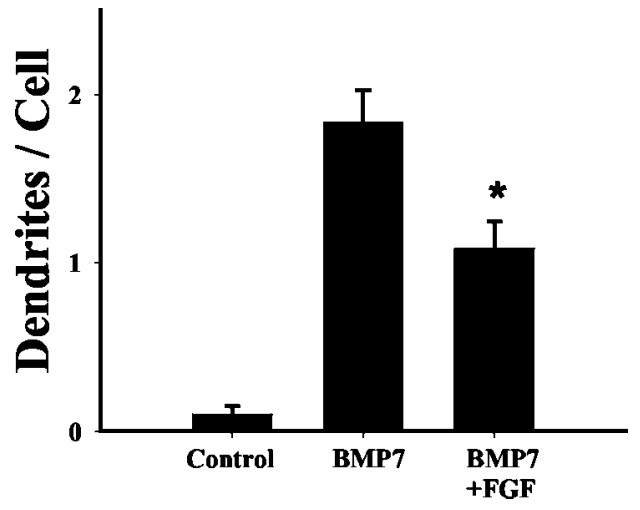

Figure 9. FGF inhibits BMP-7-induced dendritic growth. Sympathetic neurons were cultured in the control media containing $10 \mathrm{ng} / \mathrm{ml} \mathrm{NGF}$ to maintain cell survival. After elimination of non-neuronal cells, neurons were exposed to BMP-7 $(5 \mathrm{ng} / \mathrm{ml})$ with or without FGF (100 $\mathrm{ng} / \mathrm{ml}$ ). 0 n day 5 , cellular morphology ( $n \geq 60$ cells) was assessed by immunostaining using mAb to MAP2. ${ }^{*} p<0.05$ versus BMP-7.

total dendritic arbor of $\sim 13 \mu \mathrm{m}$ ) and that $\mathrm{KCl}$ provided only a moderate enhancement of dendritic growth (total arbor of $\sim 23$ $\mu \mathrm{m})$. In contrast, the amount of dendritic growth in our BMP7 -treated cultures $(\sim 300 \mu \mathrm{m}$ in $5 \mathrm{~d})$ was an order of magnitude greater, and indeed the rate of growth was close to that observed in vivo (Lein et al., 1995). Thus, although there may be circumstances in which depolarization-induced ERK activation can stimulate dendritic growth, such as the refinement of terminal processes, it is likely that opposite effects dominate when there is rapid expansion of the dendritic arbor.

Sympathetic neurons require NGF for their survival (LeviMontalcini, 1987; Deckwerth and Johnson, 1993). Therefore, most tissue culture media contain a saturating concentration of this trophic factor. In agreement with others (Huang and Reichardt, 2001; Chao, 2003), we found that NGF activates the MEK pathway and thereby causes the phosphorylation of ERK1/2. Surprisingly, two pharmacological inhibitors of the ERK pathway and a dominant-negative mutant of MEK1 stimulated dendritic growth, indicating that the effect of ERK activation on dendrites is inhibitory. In contrast, NGF is known to stimulate dendritic growth in vivo and in vitro (Purves et al., 1988; Snider, 1988; Lein et al., 1995). This apparent contradiction is probably explained by the fact that NGF activates multiple signal transduction cascades via trkA receptors, including the ras/ERK pathway, PI-3 kinase/Akt kinase pathway, and PLC- $\gamma 1$ (Segal and Greenberg, 1996; Huang and Reichardt, 2001). Of particular interest is PI-3 kinase/Akt signaling. Because it is required for survival and neuronal hypertrophy (Crowder and Freeman, 1998; Mazzoni et al., 1999; Kuruvilla et al., 2000; Tsui-Pierchala et al., 2000), it seems a reasonable candidate for mediating increased dendritic growth by NGF. Our finding that an inhibitor of the PI-3 kinase pathway inhibits dendritic growth is consistent with this hypothesis. Similarly, in a previous study (Drahushuk et al., 2002), we found that an inhibitor of PLC reduced BMP-induced dendritic growth. These data suggest that the net effects of NGF on dendritic growth represent the sum of an inhibitory signaling component via ERK signaling and stimulatory signals from other trk- or p75-mediated signaling pathways. In this respect, it is important to note that the MEK/ERK and the PI-3 kinase/Akt pathways are often simultaneously activated in response to growth factors and hormones, and, although the most frequent interaction between these two pathways is synergistic, there are also many instances (Kauffmann-Zeh et al., 1997; Rommel et al., 1999) in which they have been found to function in an antagonistic 

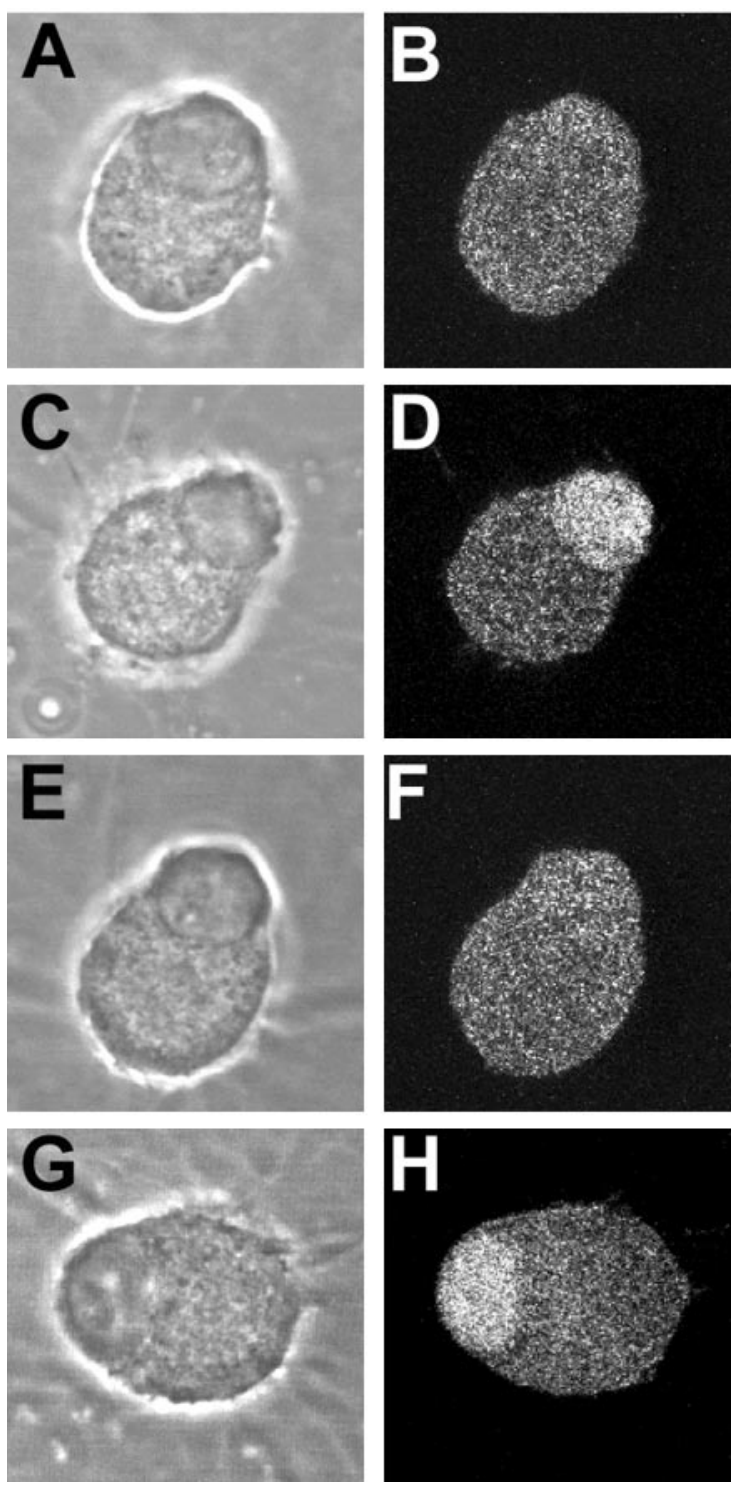

Figure 10. Inhibition of MEK1 increases the nuclear accumulation of Smad-1. Sympathetic neurons were cultured under control conditions $(A, B)$ or in the presence of a maximally effective dose of BMP-7 (100 ng/ml) $(C, D)$ for $2 \mathrm{hr}$. In addition, cultures were treated with BMP-7 at a concentration $(10 \mathrm{ng} / \mathrm{ml})$ close to $\mathrm{ED}_{50}$ in the presence $(G, H)$ or absence $(E, F)$ of PD 98059. PD $98059(10 \mu \mathrm{M})$ was added 30 min before BMP-7 was maintained in the medium thereafter. Cells were immunostained with an antibody that reacts with Smad-1, and optical sections (1 $\mu \mathrm{m})$ were obtained with a Bio-Rad confocal microscope. Phase-contrast $(A, C, E, G)$ and fluorescence $(B, D, F, H)$ micrographs.

manner in non-neuronal tissues. For example, inhibition of insulinlike growth factor (ILGF)-induced ERK activation increases myogenic differentiation, whereas inhibition of ILGF-induced Akt activation decreases myogenic differentiation (Coolican et al., 1997). Such opposing interactions offer the potential for fine tuning critical cellular functions, such as dendritic growth and synapse formation. Moreover, they allow potential integration of signaling pathways activated by growth factors, transmitters, and activity.

Recent studies suggest that neurotrophins activate different signaling pathways depending on the location of stimulation and that these may have different cellular consequences. Watson et al. (2001) showed that direct application of NGF to the cell body induces phosphorylation and nuclear translocation of both ERK1/2 and ERK5. In contrast, exposure of axon terminals to
NGF caused rapid activation of only ERK5 in the cell body. Similarly, the effects of BDNF on dendritic growth in retinal ganglion cells vary depending on its source (Lom and Cohen-Cory, 1999; Lom et al., 2002): dendritic growth is promoted by target-derived BDNF, whereas it is inhibited by locally applied BDNF. Our data indicate that the inhibitory effects of ERK on dendritic growth are mediated by ERK1/2 and that ERK5 is not involved, suggesting that it is local ERK activation occurring in the cell body or dendrites rather than axon terminals that is inhibitory for sympathetic neurons. In this respect, it is important to note that other activators of the ERK pathway, such as FGF, can also inhibit dendritic growth and that preganglionic sympathetic nerve terminals contain peptides, such as PACAP (pituitary adenylate cyclase-activating polypeptide) and VIP (Baldwin et al., 1991; Sasek et al., 1991; Beaudet et al., 1998) that are known to cause ERK activation (Frodin et al., 1994; Young et al., 1994; Barrie et al., 1997) and to inhibit dendritic growth (Drahushuk et al., 2002).

The cellular mechanism by which ERK signaling affects BMP7-induced dendritic growth may involve interactions with proteins involved in BMP signaling. We found that treatment with PD 98059 enhances the nuclear accumulation of Smad-1 in response to a low concentration of BMP-7 and that it increases nuclear accumulation to a degree comparable with that of cultures treated with a maximally effective concentration of BMP-7. These data suggest that ERKs negatively affect the transcriptional activity of Smad-1. Similarly, Kretzschmar et al. (1997) reported that activation of the ERK pathway inhibits the nuclear accumulation of Smad-1 by causing phosphorylation of the hinge region linking the inhibitory and effector domains of Smad1. This phosphorylation site is separate and distinct from the C-terminal sequence of Smad-1 phosphorylated by the BMP-7 receptor. However, it plays a critical role in regulating Smad-1 activity (Kretzschmar et al., 1997). In addition, oncogenic Ras represses TGF- $\beta$ signaling through downregulation of Smad-4, the common-partner Smad (Saha et al., 2001), which is mediated by the activation of ERK pathway. Thus, interactions between ERKs and downstream mediators of BMP signaling may account for some of the inhibitory effects of ERK activation on dendritic growth in sympathetic neurons.

\section{References}

Adams JP, Sweatt JD (2002) Molecular psychology: roles for the ERK MAP kinase cascade in memory. Annu Rev Pharmacol Toxicol 42:135-163.

Anderson CN, Tolkovsky AM (1999) A role for MAPK/ERK in sympathetic neuron survival: protection against a p53-dependent, JNK-independent induction of apoptosis by cytosine arabinoside. J Neurosci 19:664-673.

Atwal JK, Massie B, Miller FD, Kaplan DR (2000) The TrkB-Shc site signals neuronal survival and local axon growth via MEK and P13-kinase. Neuron 27:265-277.

Baker RE, Dijkhuizen PA, Van Pelt J, Verhaagen J (1998) Growth of pyramidal, but not non-pyramidal, dendrites in long-term organotypic explants of neonatal rat neocortex chronically exposed to neurotrophin-3. Eur J Neurosci 10:1037-1044.

Baldwin C, Sasek CA, Zigmond RE (1991) Evidence that some preganglionic sympathetic neurons in the rat contain vasoactive intestinal peptideor peptide histidine isoleucine amide-like immunoreactivities. Neuroscience 40:175-184.

Barrie AP, Clohessy AM, Buensuceso CS, Rogers MV, Allen JM (1997) Pituitary adenylyl cyclase-activating peptide stimulates extracellular signalregulated kinase 1 or 2 (ERK1/2) activity in a Ras-independent, mitogenactivated protein kinase/ERK kinase 1 or 2-dependent manner in PC12 cells. J Biol Chem 272:19666-19671.

Beaudet MM, Braas KM, May V (1998) Pituitary adenylate cyclase activating polypeptide (PACAP) expression in sympathetic preganglionic projection neurons to the superior cervical ganglion. J Neurobiol 36:325-336. 
Belliveau DJ, Krivko I, Kohn J, Lachance C, Pozniak C, Rusakov D, Kaplan D, Miller FD (1997) NGF and neurotrophin-3 both activate TrkA on sympathetic neurons but differentially regulate survival and neuritogenesis. J Cell Biol 136:375-388.

Bergmann A, Agapite J, McCall K, Steller H (1998) The Drosophila gene hid is a direct molecular target of Ras-dependent survival signaling. Cell 95:331-341.

Bruckenstein DA, Higgins D (1988a) Morphological differentiation of embryonic rat sympathetic neurons in tissue culture. I. Conditions under which neurons form axons but not dendrites. Dev Biol 128:324-336.

Bruckenstein DA, Higgins D (1998b) Morphological differentiation of embryonic rat sympathetic neurons in tissue culture. II. Serum promotes dendritic growth. Dev Biol 128:337-348.

Chandrasekaran V, Zhai Y, Wagner M, Kaplan PL, Napoli JL, Higgins D (2000) Retinoic acid regulates the morphological development of sympathetic neurons. J Neurobiol 42:383-393.

Chao M (2003) Neurotrophins and their receptors: a convergence point for many signaling pathways. Nat Rev Neurosci 4:299-309.

Coolican SA, Samuel DS, Ewton DZ, McWade FJ, Florini JR (1997) The mitogenic and myogenic actions of insulin-like growth factors utilize distinct signaling pathways. J Biol Chem 272:6653-6662.

Cowley S, Paterson H, Kemp P, Marshall CJ (1994) Activation of MAP kinase kinase is necessary and sufficient for PC12 differentiation and for transformation of NIH 3T3 cells. Cell 77:841-852.

Creedon DJ, Johnson EM, Lawrence JC (1996) Mitogen-activated protein kinase-independent pathways mediate the effects of nerve growth factor and cAMP on neuronal survival. J Biol Chem 271:20713-20718.

Crowder RJ, Freeman RS (1998) Phosphatidylinositol 3-kinase and Akt protein kinase are necessary and sufficient for the survival of nerve growth factor-dependent sympathetic neurons. J Neurosci 18:2933-2943.

Deckwerth TL, Johnson Jr EM (1993) Neurotrophic factor deprivationinduced death. Ann NY Acad Sci 679:121-131.

Drahushuk K, Connell TD, Higgins D (2002) Pituitary adenylate cyclaseactivating polypeptide and vasoactive intestinal peptide inhibit dendritic growth in cultured sympathetic neurons. J Neurosci 22:6560-6569.

Esquenazi S, Monnerie H, Kaplan P, Le Roux P (2002) BMP-7 and excess glutamate: opposing effects on dendrite growth from cerebral cortical neurons in vitro. Exp Neurol 176:41-54.

Feany MB, Lee S, Edwards RH, Buckley KM (1992) The synaptic vesicle protein SV2 is a novel type of transmembrane transporter. Cell 70:861-867.

Fletcher TL, De Camilli P, Banker G (1994) Synaptogenesis in hippocampal cultures: evidence indicating that axons and dendrites become competent to form synapses at different stages of neuronal development. J Neurosci 14:6695-6706.

Frodin M, Peraldi P, Van Obberghen E (1994) Cyclic AMP activates the mitogen-activated protein kinase cascade in PC12 cells. J Biol Chem 269:6207-6214.

Gratacos E, Gavalda N, Alberch J (2002) Bone morphogenetic protein 6 is a neurotrophic factor for calbindin-positive striatal neurons. J Neurosci Res 70:638-644.

Grewal SS, York RD, Stork PJ (1999) Extracellular-signal-regulated kinase signalling in neurons. Curr Opin Neurobiol 9:544-553.

Guo X, Lein P, Higgins D (1998) Osteogenic protein 1 and related bone morphogenetic proteins regulate dendritic growth and the expression of MAP 2 in sympathetic neurons. Neurosci Lett 245:131-134.

Guo X, Chandrasekaran V, Lein P, Kaplan PL, Higgins D (1999) Leukemia inhibitory factor and ciliary neurotrophic factor cause dendritic retraction in cultured rat sympathetic neurons. J Neurosci 19:2113-2121.

Hansen TO, Rehfeld JF, Nielsen FC (2000) Cyclic AMP-induced neuronal differentiation via activation of $\mathrm{p} 38$ mitogen-activated protein kinase. J Neurochem 75:1870-1877.

Higgins D, Lein PJ, Osterhout DJ, Johnson MI (1991) Tissue culture of mammalian autonomic neurons. In: Culturing nerve cells (Banker G, Goslin K, eds), pp 177-205. Cambridge, MA: MIT.

Higgins D, Burack M, Lein P, Banker G (1997) Mechanisms of neuronal polarity. Curr Opin Neurobiol 7:599-604.

Huang EJ, Reichardt LF (2001) Neurotrophins: roles in neuronal development and function. Annu Rev Neurosci 24:677-736.

Kato Y, Kravchenko VV, Tapping RI, Han J, Ulevitch RJ, Lee JD (1997) BMK1/ERK5 regulates serum-indcued early gene expression through transcription factor MEF2C. EMBO J 16:7054-7066.
Kauffmann-Zeh A, Rodriguez-Viciana P, Ulrich E, Gilbert C, Coffer P, Downward J, Evan G (1997) Suppression of c-myc-induced apoptosis by Ras signaling through PI(3)K and PKB. Nature 385:544-548.

Kim IJ, Beck HN, Lein PJ, Higgins D (2002) Interferon gamma induces retrograde dendritic retraction and inhibits synapse formation. J Neurosci 22:4530-4539.

Kretzschmar M, Doody J, Massague J (1997) Opposing BMP and EGF signalling pathways converge on the TGF-beta family mediator Smad1. Nature 389:618-622.

Kurada P, White K (1998) Ras promotes cell survival in Drosophila by downregulating hid expression. Cell 95:319-329.

Kuruvilla R, Ye H, Ginty DD (2000) Spatially and functionally distinct roles of the PI3-K effector pathway during NGF signaling in sympathetic neurons. Neuron 27:499-512.

Lein P, Johnson M, Guo X, Rueger D, Higgins D (1995) Osteogenic protein-1 induces dendritic growth in rat sympathetic neurons. Neuron 15:597-605.

Lein P, Drahushuk K, Higgins D (2002) Effects of bone morphogenetic proteins on neural tissues. In: Bone morphogenetic proteins (Vukicevic S, Sampath KT, eds), pp 289-319. Basel: Birkhauser Verlag.

Levi-Montalcini R (1987) The nerve growth factor 35 years later. Science 237:1154-1162.

Lom B, Cohen-Cory S (1999) Brain-derived neurotrophic factor differentially regulates retinal ganglion cell dendritic and axonal arborization in vivo. J Neurosci 19:9928-9938.

Lom B, Cogen J, Sanchez AL, Vu T, Cohen-Cory S (2002) Local and targetderived brain-derived neurotrophic factor exert opposing effects on the dendritic arborization of retinal ganglion cells in vivo. J Neurosci 22:7639-7649.

Mansour SJ, Matten WT, Hermann AS, Candia JM, Rong S, Fukasawa K, Vande Woude GF, Ahn NG (1994) Transformation of mammalian cells by constitutively active MAP kinase kinase. Science 265:966-970.

Mazzoni IE, Said FA, Aloyz R, Miller FD, Kaplan D (1999) Ras regulates sympathetic neuron survival by suppressing the p53-mediated cell death pathway. J Neurosci 19:9716-9727.

McAllister AK, Lo DC, Katz LC (1995) Neurotrophins regulate dendritic growth in developing visual cortex. Neuron 15:791-803.

Miura T, Tanaka S, Seichi A, Arai M, Goto T, Katagiri H, Asano T, Oda H, Nakamura K (2000) Partial functional recovery of paraplegic rat by adenovirus-mediated gene delivery of constitutively active MEK1. Exp Neurol 166:115-126.

Morooka T, Nishida E (1998) Requirement of p38 mitogen-activated protein kinase for neuronal differentiation in PC12 cells. J Biol Chem 273:24285-24288.

Pang L, Sawada T, Decker SJ, Saltiel AR (1995) Inhibition of MAP kinase kinase blocks the differentiation of PC-12 cells induced by nerve growth factor. J Biol Chem 270:13585-13588.

Purves D, Snider WD, Voyvodic JT (1988) Trophic regulation of nerve cell morphology and innervation in the autonomic nervous system. Nature 336:123-128.

Rommel C, Clark BA, Zimmermann S, Nunez L, Rossman R, Reid K, Moelling K, Yancopoulos GD, Glass DJ (1999) Differentiation stage-specific inhibition of the Raf-MEK-ERK pathway by Akt. Science 286:1738-1741.

Saha D, Datta PK, Beauchamp RD (2001) Oncogenic ras represses transforming growth factor-beta /Smad signaling by degrading tumor suppressor Smad4. J Biol Chem 276:29531-29537.

Sasek CA, Baldwin C, Zigmond RE (1991) Distribution of vasoactive intestinal peptide- and peptide histidine isoleucine amide-like immunoreactive neurons and fibers in the thoracic spinal cord of the rat. Brain Res 567:159-164.

Schwartz PM, Borghesani PR, Levy RL, Pomeroy SL, Segal RA (1997) Abnormal cerebellar development and foliation in $\mathrm{BDNF}-/-$ mice reveals a role for neurotrophins in CNS patterning. Neuron 19:269-281.

Segal RA, Greenberg ME (1996) Intracellular signaling pathways activated by neurotrophic factors. Annu Rev Neurosci 19:463-489.

Sjogreen B, Wiklund P, Ekstrom PA (2000) Mitogen activated protein kinase inhibition by PD 98059 blocks nerve growth factor stimulated axonal outgrowth from adult mouse dorsal root ganglia in vitro. Neuroscience 100:407-416.

Snider WD (1988) Nerve growth factor enhances dendritic arborization of sympathetic ganglion cells in developing mammals. J Neurosci 8:2628-2634.

Traverse S, Gomez N, Paterson H, Marshall C, Cohen P (1992) Sustained activation of the mitogen-activated protein (MAP) kinase cascade may be re- 
quired for differentiation of PC12 cells. Comparison of the effects of nerve growth factor and epidermal growth factor. Biochem J 288:351-355.

Tsui-Pierchala BA, Putcha GV, Johnson Jr EM (2000) Phosphatidylinositol 3-kinase is required for the trophic, but not the survival-promoting, actions of NGF on sympathetic neurons. J Neurosci 20:7228-7237.

Vaillant AR, Zanassi P, Walsh GS, Aumont A, Alonso A, Miller FD (2002) Signaling mechanisms underlying reversible, activity-dependent dendrite formation. Neuron 34:985-998.

Virdee K, Tolkovsky AM (1996) Inhibition of p42 and p44 mitogenactivated protein kinase activity by PD98059 does not suppress nerve growth factor-induced survival of sympathetic neurones. J Neurochem 67:1801-1805.

Watson FL, Heerssen HM, Bhattacharyya A, Klesse L, Lin MZ, Segal RA
(2001) Neurotrophins use the Erk5 pathway to mediate a retrograde survival response. Nat Neurosci 4:981-988.

Wiklund P, Ekstrom PA, Edstrom A (2002) Mitogen-activated protein kinase inhibition reveals differences in signalling pathways activated by neurotrophin- 3 and other growth-stimulating conditions of adult mouse dorsal root ganglia neurons. J Neurosci Res 67:62-68.

Withers GS, Higgins D, Charette M, Banker G (2000) Bone morphogenetic protein-7 enhances dendritic growth and receptivity to innervation in cultured hippocampal neurons. Eur J Neurosci 12:106-116.

Young SW, Dickens M, Tavare JM (1994) Differentiation of PC12 cells in response to a cAMP analogue is accompanied by sustained activation of mitogen-activated protein kinase. Comparison with the effects of insulin, growth factors and phorbol esters. FEBS Lett 338:212-216. 